\title{
Bibliografia Comentada: \\ Novos movimentos Sociais e \\ Comunicação: uma aproximação \\ temática
}

Rafael Gioielli

Resumo - A sociedade brasileira de hoje parece rumar cada vez mais para a ausência de espaços públicos, nos quais os homens reunidos cara a cara possam, através do debate racional e coletivo, definir os rumos da coletividade. Um novo tipo de espaço público emerge, neste contexto, agora mediado pelos meios de comunicação e invadido pelas questões sociais, resultado das pressões e dos conflitos evidenciados, principalmente, pela atuação dos movimentos sociais. Nessa realidade, os media constituem-se um espaço privilegiado de poder e a comunicação popular apresenta-se como uma alternativa aos meios de comunicação de massa, monopolizados e atuando $\mathrm{cm}$ consonância com o status quo.

\section{Introdução}

Neste processo, mais do que evidenciar os conflitos, os novos movimentos sociais e a comunicação popular, a partir de suas práticas diárias, contribuem para a criação de uma nova prática socio-cultural. É no cotidiano das pessoas envolvidas nestas iniciativas que se enraíza esta nova prática sociocultural, espaço em que começa a despontar um novo entendimento de cidadania.

A crescente importância dos movimentos sociais na sociedade contemporânea, sobretudo dos novos movimentos sociais surgidos nas últimas décadas, trouxe inevitavelmente esta questão para dentro dos estudos de comunicação e política. A análise e conhecimento destes movimentos e sua relação com a questão da cultura c do espaço público vem ampliando e subsidiando novos olhares e estudos em comunicação. Talvez por isso, seja importante resgatar algumas características dos novos movimentos sociais e os caminhos para o qual este estudo pode levar as pesquisas em comunicação.

$\mathrm{O}$ texto que aqui apresento não se trata dc comentários ou resenhas sobre textos específicos, mas é uma busca, a partir do estudo dc algumas obras, de traçar um novo caminho de aproximação do estudo dos novos movimentos sociais com os estudos de comunicação. De certo que outras abordagens e outras obras e autores poderiam ser usadas nessa busca, dos direitos sociais. Com a instalação do Estado mínimo neoliberal, a estrutura estatal que garantia estes direitos é desmontada e a saúde, a educação, a previdência, etc. são transferidas para a iniciativa privada. Além disso, possibilita-se a flexibilização dos acordos entre patrões e empregados sinalizando um retrocesso a todas as conquistas trabalhistas alcançadas na modernidade. Os cidadãos, que antes tinham os serviços sociais como direitos garantidos pelo Estado, passam a ser consumidores destes serviços, oferecidos agora pela iniciativa privada.

Em alguns países como o Brasil, estes dois estágios convivem. Mesmo sem ter tido de fato a instalação de um Estado nação que funcionasse, já se vive a implantação de um Estado mínimo, e aquilo que nem se concretizou verdadeiramente como direito fica cada vez mais difícil de ser conquistado. "Se nos países centrais (os novos movimentos sociais) combinam democracia participativa e valores e reivindicações pós-materialistas, na América Latina combinam, na maioria das situações, democracia participativa com valores ou reivindicações de direitos básico. "' 
É neste contexto que os novos movimento sociais, se caracterizam por serem iniciativas da sociedade civil que se organiza buscando pressionar $\mathrm{o}$ Estado a garantir direitos, sejam eles a igualdade de direitos civis para negros, mulheres e minorias, aparelhos urbanos como moradia e saneamento, o emprego, a assistência social e, até mesmo estabelecem novos direitos, como por exemplo o direito ao meio ambiente equilibrado ${ }^{2}$. São denominados novos pois apresentam a emergência de novos sujeitos sociais e de novas práticas de mobilização social, figurando como alternativa às formas tradicionais de organização da sociedade civil, marcadas pelos partidos políticos e pelos sindicatos ${ }^{3}$.

$\mathrm{Na}$ verdade, figuram, inclusive, como resposta à crise de representatividade política. Os cidadãos, não crendo mais nas possibilidades dos partidos e dos políticos eleitos em resolverem seus inúmeros problemas, mobilizam-se para criar novos mecanismos de pressão.

Apresentam-se segmentados e, ao contrário dos partidos, não possuem um projeto global de transformação social. Também não atuam formalmente na esfera da sociedade política. Agem na esfera da sociedade civil, organizando a ação da população em tomo de objetivos concretos. Segundo Santos, “(...) em relação ao Estado mantêm uma distância calculada, simétrica da que mantêm em relação aos partidos e aos sindicatos tradicionais." 4

Não se organizam com base nas classes sociais e sim a partir de grupos sociais transclassistas. "Ao identificar novas formas de opressão que extravasam das relações de produção e nem sequer são especificas delas, como sejam a guerra, a poluição, o machismo o racismo ou o produtivismo (...), os NMSs denunciam, com uma radicalidade sem precedentes, os excessos de regulação da modernidade". 5

São efêmeros uma vez que, organizados a partir de reivindicações pontuais, prevêem mudanças rápidas $\mathrm{e}$ imediatas. Ainda segundo Santos, "a emancipação por que se luta visa transformar o quotidiano das vitimas da opressão aqui e agora e não num futuro longínquo."6 A obtenção de vitória nas suas reivindicações, podese dizer, representa também o término daquela organização especifica, uma vez que não há mais um objetivo comum que justifique a manutenção de tal movimento. Em contrapartida, a mesma vitória dá força para que aqueles cidadãos se organizem em outros movimentos, pautados em tomo de outras reivindicações.

Vale ressaltar que os novos movimentos sociais trazem consigo uma importante mudança na cultura política da sociedade contemporânea: o "alargamento da política para além do marco liberal da distinção entre Estado e sociedade civil." "̈ É a politização da vida cotidiana do indivíduo e a inovação e superação das formas tradicionais de participação política. " $A$ politização do social, do cultural $e$, mesmo, do pessoal abre um campo imenso para o exercício da cidadania e revela, no mesmo passo, as limitações da cidadania de extracção liberal, inclusive da cidadania social, circunscrita ao marco do Estado e do político por ele constituido."?"8

Estes no vos movimentos sociais, pouco a pouco, trazem consigo uma nova realidade de democracia. Evidenciam a existência das diferenças e colocam em prática sua convivência e negociação. Não só diferenças étnicas, culturais e religiosas emergem, mas as diferenças sociais também. Ter de negociar com seus pares e com outros movimentos os rumos da coletividade traz para o cidadão a vivência explicita da democracia participativa e embute uma nova prática social em que o debate e a aceitação da diferença se fazem fundamentais.

É importante realçar que os novos movimentos sociais se colocam como lugar privilegiado de conflito no interior da sociedade, uma vez que aglutinam e organizam as lutas sociais frente ao Estado. Trazem à tona a existência de excluídos e de uma sociedade desigual, na qual muitos são desprovidos dos direitos básicos garantidos por lei. São os responsáveis por uma relação de questionamento e tensão entre sociedade civil e Estado de onde emerge um novo espaço de conflito e negociação,
(2) Vide DAGNINO, Evelina. Op. at, p.103-115.

(3) C. SANTOS, Boaventura de Sousa. Op. at CARDOSO, Ruth Conêa Leite. "A Trajetória dos Movimentos Sociais". In: DAGNINO, Evelina(org.). Anos 90/Política e Sociedade no Brasil. Ed. Brasiliense, São Paulo, 1994, p. 81-

(4) SANTOS, Boaventura de Sousa, Op. at, p. 261.

(5) Id.,p. 258.

(6) $I b ., p .259$.

(7) $I b ., p .263$.

(8) Ib.,p.263. 
um novo espaço público e uma nova prática da cidadania.

\section{Sociedade mediática,} Movimentos sociais, e novos espaços públicos

$\mathrm{Na}$ sociedade contemporânea, a comunicação tornou-se espaço privilegiado de poder. A ausência de espaços para o encontro presencial, cara a cara e para o debate racional entre os cidadão, somada a presença quase "onipresente" e mediadora dos media, trouxe para os meios de comunicação um papel fundamental no espaço público contemporâneo.

Além disso, a crise do sistema político representativo e a presença dos novos movimentos sociais como focos permanentes de conflito trazem novos e importantes elementos ao estudo do espaço público. Defini-lo na contemporaneidade não é um objetivo fácil ou inquestionável. Está sujeito a equívocos e imprecisões, porque lida com a busca de novos mecanismos para entender o exercício da política $\mathrm{c}$ da cidadania na sociedade.

Nossa sociedade caracteriza-se pelo sistema democrático representativo, no qual o cidadão é levado às urnas para escolher aqueles que o representarão na esfera da sociedade política. A incapacidade do Estado cm garantir os direitos básicos dos cidadãos, agravada pelo distanciamento da prática dos políticos dos ideais que os elegeram coloca em crise este modelo.

Os partidos políticos, distanciados dos eleitores e do mundo da sociedade civil, não mais correspondem aos anseios da população. O discurso ideológico, generalista e abrangente, mostrase ineficaz no combate às mazelas da sociedade e na garantia dc direitos.

Já o cidadão eleito muitas vezes deixa de ser um representante da população que o elegeu e assume um papel de político profissional, utilizando-se do poder que lhe é concedido em benefício próprio ou de pequenos grupos. $\mathrm{O}$ eleitor não reconhece nos políticos eleitos seus representantes e o processo de escolha não se fundamenta necessariamente na identidade de idéias e propostas.
Os altos índices de corrupção e o desvio das ações do Estado dos interesses e expectativas da sociedade civil, também contribuem para colocar $\mathrm{cm}$ xeque todo este sistema. $\mathrm{O}$ cidadão já não crê que representantes possam fazer algo por ele. Neste contexto, o voto perde sua importância e não se vislumbra a possibilidade de transformação da sociedade a partir dele. Santos entende que "a representação democrática perdeu o contato com os anseios e as necessidades da população representada e fez-se refém dos interesses corporativos poderosos. Com isto, os cidadãos alhearam-se da representação sem, no entanto, terem desenvolvido novas formas de representação política, exercitáveis em áreas políticas novas e mais amplas. "9

$\stackrel{E}{E}$ diante deste quadro, que a sociedade civil se organiza na tentativa dc garantir seus interesses e direitos frente a um Estado omisso. É aí que se registra o aparecimento dos novos movimentos sociais, figurando como novos atores sociais no jogo democrático. São pontuais em suas críticas e reivindicações e negociam com o Estado, não mais soberano ou absoluto, a implementação de seus projetos. E é no espaço desta negociação que se estabelece o novo espaço público. Não se trata mais de um debate no qual as questões são colocadas de maneira universal. Elas são negociadas pontual e simultaneamente em espaços distintos, e este espaço público, então, torna-se fragmentado e parcial. Para Miège, este novo espaço público que emerge "seria uma resposta à crise da representação política e à apatia crescente dos cidadãos".'10

Como já foi apontado, os meios de comunicação exercem um papel social fundamental na sociedade contemporânea. São eles, a partir de seu alcance por toda a sociedade, que conferem visibilidade aos fatos. São parte constituinte deste novo espaço público que emerge à medida em que se colocam como elemento mediador na publicização dos debates em pauta. A legitimidade de uma questão está ligada também a visibilidade que obtiver nos 
media. Assim, não só o sucesso como a própria existência da negociação entre a sociedade civil organizada e o Estado depende do nível de visibilidade que conseguir atingir. É com a difusão pela opinião pública que ganham vida as questões do espaço público.

Este novo espaço público fragmentado é também plural, tornando-se objeto de interesses diversos, dado que apresenta a ampliação dos conflitos. Daí acentua-se ainda mais o papel mediador dos media. Diante de uma gama gigantesca de negociações e conflitos, são os meios de comunicação que definem aqueles que estarão na ordem do dia, acirrando uns, abafando outros. São os media que têm o poder de escolher quais questões estarão sendo expostas à opinião pública, priorizando, de acordo com seus interesses, umas em relação a outras.

Aqui o público figura como aquilo que se busca como consenso, como normativo ante o diverso. E o espaço do privado volta-se ao individual, ao intimo e pessoal.

As questões destes novos espaços públicos, por sua vez, giram em tomo de questões de ordem social. São direitos básicos como a moradia, o transporte, o trabalho e a ecologia que são colocados em pauta. A partir do momento em que o espaço público toma-se palco da negociação e da implementação dos aparelhos básicos urbanos, ou atem-se a negociação de questões como os direitos humanos e a ecologia, temos a invasão do espaço político pelas questões sociais. Fenômeno denominado por Beaud de a politização do social: "politizado, o social penetra a política, que se torna seu objeto mesmo, donde o espaço público". ${ }^{11}$

No contexto dessa sociedade mediática, em que a comunicação figura como espaço privilegiado de poder, dada sua centralidade como elemento mediador do espaço público, mas apresenta-se organizada em grandes grupos internacionais nos quais o interesses econômicos e de mercado se sobrepõem ao interesse público, a comunicação popular e a alternativa figuram como tentativa de criação de novos elementos de visibilidade para movimentos sociais e grupos contra hegemônicos.

São inúmeras as iniciativas populares na criação de veículos dc comunicação, sejam eles rádios comunitárias, jornais, revistas e informativos alternativos impressos e eletrônicos, websites, entre outros, que procuram, além de organizar a ação dos movimentos e atrair novos militantes, dar visibilidade a fatos escamoteados pelos grande media, ganhando atenção do grande público para questões antes desconhecidas.

É nesse sentido que a comunicação popular passa a ser estratégica na ação de movimentos sociais e contribui para o alargamento do espaço de conflito e debate na sociedade mediática. O espaço público que emerge, se faz mais democrático na medida em que as iniciativas populares de comunicação se colocam como contraponto às grandes corporações internacionais de comunicação, e denunciam a própria manipulação da informação a serviço dc interesses privados. Uma das grandes contribuições desta comunicação popular é trazer para o espaço público a dimensão de um espaço privilegiado e permanente de conflito, no qual as desigualdades sociais se evidenciam.

No intuito de resumir sinteticamente as características deste espaço público emergente na sociedade mediática, podemos aqui resgatar as quatro marcas propostas por Floris:

"1. ث́ um campo de formação simbólica de uma opinião pública através de todas as formas de comunicação existentes na sociedade.

2. Ele é um campo de formação democrática de uma vontade política por meio de sufrágio universal, do parlamento e dos partidos.

3. Ele é uma esfera de mediação entre o Estado e a sociedade civil.

4. O espaço público não é um lugar abstrato do consenso democrático ideal, é um espaço conflitivo exprimindo relações sociais de desigualdade e de dominação." 12

Tem-se, então, com o advento generalizado dos media a configuração
(11) BEAUD, Paul. Medias, Mediations et Mediateurs dans la sociéte industrielle. These Dodorat D'Etat-Grenoble, France, 1985. CF. SOUSA, M.W. - "Práticas de recepção mediática como práticas de pertenaimento público". In. Rev. Novos Olhares, N03, São Paulo, 1999.

(12) FLORIS, Bemard. "Linterpretation de l'espace public et de l'enterprise". In: Pailliart, I.

(org.) - L'espace pubiic et l'emprise de communication, BLUG, Grenoble, France, 1995. CF. SOUSA, M.W. - - "Páticas de recepção mediática como práticas depertenaimento público". In. Rev. Novos Olhares, N03, São Paulo, 1999. 
de um novo espaço público, como já apontado, plural e fragmentado. Este novo espaço público constitui um novo nexo entre o público e o privado. A experiência individual, isolada, e portanto, privada de acesso aos media, na verdade configura um novo portal de acesso a algo que não se retém no privado, mas faz parte com o coletivo e com o simbólico que uma sociedade constrói na esfera real e visível, da vida coletiva.

A representação política passa a ser constituída também por esse novo nexo entre público e privado, nem sempre regulamentado, mas quase sempre fonte de atrito, de tensão e de conflito. Indicador de uma sociedade em movimento, de que há uma nova praça de conflito na qual atores competem, ainda que não no plano da racionalidade, mas do simbólico.

O espaço político através dos media ganha assim um novo estatuto na sociedade, também para os movimentos sociais e para a ação revisada do que até então se entendeu por comunicação popular.

\section{Movimentos Sociais, Comunicação Popular c Cultura}

A comunicação em sua relação com os movimentos sociais precisa ser vista dentro do âmbito da cultura. Precisa ser entendida enquanto processo cultural, no qual o diferencial para a construção de uma comunicação realmente democrática é a participação do cidadão.

Neste sentido, é que se pode dizer que os movimentos sociais ainda não entenderam completamente a dimensão e a importância da comunicação enquanto elemento da construção de uma nova cultura e de uma nova realidade.

Mais preocupados em afirmar um projeto econômico alternativo, os movimentos sociais, por vezes, reproduzem em sua prática o autoritarismo típico da sociedade capitalista, não privilegiando a participação popular efetiva e democrática na formulação de um projeto alternativo de sociedade.

Grande parte dos exemplos que temos para analisar a comunicação dos movimentos sociais, nos mostra que o uso que estes fazem daquela tem sido instrumental, o que denuncia um descompasso entre a vontade de construir uma sociedade democrática e a prática dessa construção. Enquanto deveriam desenvolver uma comunicação em que emissores e receptores estivessem em relação de igualdade, os movimentos sociais, muitas vezes, privilegiam a construção de uma comunicação vertical e autoritária negando seu próprio discurso democrático e evidenciando seu despreparo para lidar com a participação popular.

Entre os autores que se detiveram sobre esta questão está Festa. Ao analisar as inúmeras iniciativas de comunicação por parte dos movimentos sociais durante os anos 70 e 80 , a autora aponta três vetores que nortearam ações que ela chama de "utópicas". "Um que vinha de uma pretensa reapropriação de Gramsci e do nacionalpopular; outra que se pautava pela influência organizativa do Ieninismo oficial; e uma terceira, apoiada na concepção de um novo desenvolvimento auto-sustentado." "'Apesar de três vertentes diferentes, os processos comunicacionais que se desenvolveram não conseguiram fugir ao uso instrumental dos meios c das massas.

Aqueles que seguiram pela vertente gramsciniana, mesmo ao tentarem recompor um corte histórico-cultural de classe, por várias circunstâncias, deixaram em aberto as possibilidades de confrontação ideológica com o projeto cultural burguês e com a indústria cultural. Os que se situavam na vertente marxista-leninista, influenciados pelo viés do economicismo, acabaram, segundo a autora, construindo estruturas verticais de poder que se materializavam também na comunicação. "Experiências de comunicação alternativa e popular constituíram-se, na maioria dos casos, como ação instrumental e como parte do aparato institucional do fazer politico. O economicismo e as concepções politicas foram incapazes de incorporar a cultura como esfera de poder. "14

Quando analisa as iniciativas alavancadas sobretudo pelas ONGs e financiadas por instituições de ajuda 
internacional, cujo mote era desenvolvimentista e de cooperação, Festa identifica um tipo de comunicação que privilegiou a técnica sobre o conteúdo. Eram manuais de como fazer seu jornal, revista, rádio etc. Aqui não se pensava a comunicação para além do uso técnico dos meios, não se pensava a comunicação enquanto processo cultural.

Portanto, até os anos 90, mesmo com inúmeras iniciativas por parte de movimentos sociais na área da comunicação, a dimensão cultural era abafada pela ação política e a comunicação acabava sendo utilizada apenas como processo instrumental desta ação. Ainda não se vislumbrava na prática a dimensão cultural da comunicação e a necessidade de trabalhar a cultura no processo revolucionário. $\mathrm{Na}$ verdade, reproduziase a mesma comunicação feita pelos grandes veículos e que tanto se criticava.

Outra pesquisadora que se deteve sobre esta temática é Peruzzo. A autora, no entanto, adverte que não deixam de ocorrer experiências avançadas envolvendo efetivamente a participação da população e que contribuem para a construção de uma comunicação popular, de significado político inovador, à medida em que é realmente útil ao processo de construção de uma nova cultura de cidadania.

Estas iniciativas bem sucedidas de comunicação popular trazem importantes contribuições para a transformação social. Primeiro, porque são a materialização do processo de democratização da comunicação ao passo em que: diversificam o leque de opções para os receptores; desmitificam o processo de produção ao possibilitarem a participação popular na produção da informação; colocam em pauta outros valores, conteúdos e conceitos; servem de contraponto aos meios massivos; funcionam com uma mentalidade de serviço público. Segundo, porque contribuem para a formação de uma nova cultura popular, mais próxima do indivíduo e com a participação dele. Isso se dá na medida em que está comunicação popular não é um espetáculo a que se assiste, mas do qual se participa. Também porque representa um novo espaço de encontro para as comunidades, possibilitando a articulação da cultura, a reelaboração dc valores, a preservação da memória e a formação de identidades.

A comunicação dos movimentos sociais populares, por fim, contribui para a conquista da cidadania. A participação na construção desta comunicação que atua a serviço das transformações sociais, mostra para o cidadão que o exercício da cidadania não é só a escolha de seus representantes "mas também aprender a participar politicamente da leitura do bairro e da escola para os filhos, a apresentar sua canção e seu desejo de mudança, a denunciar condições indignas, a exigir seus direitos a usufruir da riqueza gerada por todos, por meio de melhores beneficios sociais e de salários mais justos, a organizar-se e a trabalhar coletivamente."15

Claro está que esta não é uma conquista apenas da comunicação popular, mas de um processo cultural de participação democrática que perpassa as relações humanas criadas no interior dos movimentos sociais e que se reflete nos processos comunicacionais que se estabelecem a partir deles.

\section{Conclusão}

Esta é apenas uma perspectiva dc como os estudos de comunicação podem ser enriquecidos com $\mathrm{O}$ cruzamento dc outras vertentes $\mathrm{dc}$ estudo como é o caso os novos movimentos sociais. A busca de novos olhares para a compreensão da sociedade mediática que se estabelece no início deste novo século pressupõe a busca de novos aportes e novas aproximações conceituais. $\mathrm{O}$ que se quis com este texto, mais do que comentar ou discutir uma bibliografia, foi a tentativa de propor um novo caminho para o estudo da comunicação, cujo resultado ainda precisa ser maturado, mas que já se coloca como algo interessante. 


\section{Bibliografia do artigo}

BEAUD, Paul. Medias, Mediations et Mediateurs dans la sociéte industrielle. These Doctorat D'Etat - Grenoble, France, 1985.

BOBBIO, Norberto. O futuro da democracia. Uma defesa das regras do jogo. Ed. Paz e Terra, Rio de Janeiro, 1989.

DAGNINO, Evelina (org.). Anos 90/Política e Sociedade no Brasil. Ed. Brasiliense, São Paulo, 1994.

FESTA, Regina Dalva. Elementos para uma análise da comunicação na América Latina: perspectivas para os anos 90. In: Comunicação \& Sociedade. Ed. IMS, São Bernardo do Campo, Março/93. Ano XI, n 19 .

FLORIS, Bernard. L'interpretation de l'espace public et de l'enterprise. In: Pailliart, I. (org.) - L'espace public et l'emprise de communication, ELLUG, Grenoble, France, 1995.

MIÈGE, B. O espaço público: perpetuado, ampliado e fragmentado. In. Rev. Novos Olhares, N³, São Paulo, 1999.

PERUZZO, C. M. Krohling. Comunicação nos movimentos populares. Ed. Vozes, Petrópolis, 1998.

SANTOS, Boaventura de S. - Pela mão de Alice, o social e o político na pós-modernidade. Ed. Cortez, São Paulo, 1997.

SOUSA, M.W. - Práticas de recepção mediática como práticas de pertencimento público. In. Rev. Novos Olhares, N³, São Paulo, 1999. 